\title{
The Planning and Compulsory Purchase Act 2004 - how will planning contributions work? II
}

by Michael Cunliffe

This paper was presented at the seminar "Planning and Compulsory Purchase Bill - the practicalities of the law", which was held by the Society for Advanced Legal Studies Planning and Environmental Law Reform Working Group on 21 April. The first part dealt with recent proposals for reform and improvement of the planning obligations system - including the clauses added to the Planning and Compulsory Purchase Bill - while the second part contains commentary by the author on the draft legislation.

\section{REFLECTIONS ON THE PLANNING CONTRIBUTION PROPOSALS}

\section{General comments}

Notwithstanding the opposition to the proposed planning contribution clauses both in the House of Commons and the House of Lords and calls for them to be deleted, the general thrust of the planning contributions clauses (cls 46, 47 and 48) did not change substantively during the passage of the Bill through Parliament save for clause 47 (the Regulations), where at the House of Lords Third Reading debate on 25 March 2004, Lord Bassam moved an amendment to recreate the existing offence of section 106(8) making it an offence to obstruct the enforcement of a planning obligation. He thought that this should be specifically included within the Act rather than in regulations and suggested an amendment to clause 47(6) accordingly.

The Government have displayed a dogged determination to seize the opportunity to legislate on the vexed area of planning contributions. It seems extraordinary that the Government should have seen fit to reintroduce a form of tariff so soon after ditching the concept.

It is even more extraordinary that the Government, having decided to introduce the optional charge, has brought forward the proposals in skeleton format without any real idea how the system will work in practice. What they should have done was to have commissioned the task force at the outset to look into the feasibility of setting an optional charge. They could have had a pilot study and come up with findings. The Government could then have come up with a suggested detailed system on which it could have sought views by way of a consultation exercise.
It is also extraordinary that the Government decided to introduce the planning contribution clauses at the very time that Kate Barker was producing her initial report including comments on the planning system and the role of planning obligations. Now that we have Kate Barker's suggestion of the planning gain supplement and her comments that the optional planning charge is very much second best, the Government is still ploughing on with its proposals for the optional charge which might be rendered nugatory by the Barker proposals.

The whole thing is a mess and the comment made by Baroness Hanham in the House of Lords that the process had been done in a "hibbledy hobbledy way" really sums it all up. The clauses that appeared were vague, the Government's intention being to deal with the details of the proposals in secondary legislation. This was unsatisfactory. Clearly it would have been better for the details to have been considered at this stage before the Bill is enacted.

The language used in the clauses is somewhat tortuous and unnatural. Planning obligations as a concept itself is somewhat strained and does not capture the essence of a "planning gain" deal. The use of the word "contribute" with the connotation of furnishing a common fund or purpose is more appropriate for a payment of money or a contribution in kind. It is not, however, a particularly helpful term in relation to a finite requirement placed upon a developer unrelated to any other contribution requirement to make a development scheme acceptable.

The optional planning charge is referred to in the legislation as "the prescribed means" and negotiated planning contributions are referred to as "the relevant requirements". Whatever happened to plain English? The intention of the legislature is to repeal sections 106, 106A 
and 106B, but at the same time to reinstate them as part of the regulations. The question arises as to whether one should keep section 106 as it is and to legislate merely for the optional charge. On the one hand planning obligations are being swept away only to be resurrected as planning obligations as one form of planning contribution under the proposed regulations. This approach has caused confusion to users of the planning system.

\section{Local authority expertise and resources}

Already over-stretched, local authorities will not have the expertise or internal resources to set up the optional charge system and to formulate suggested planning charges in their development plan documents in the absence of any actual proposals on which to base their charges. Commercial expertise may need to be bought it by local authorities from the private sector which could be an expensive exercise. It should be remembered that the local authority will need to assess possible impacts from sites within the development plan, whether or not there is a development proposed. This could be a huge task and one should bear in mind the time taken and money expended by developers in preparing transport and environmental impact assessments.

Local authorities will have to carry out major cost analyses of the infrastructure needed arising from developments likely to occur over the lifetime of a local development plan document. Councils will need to determine what proportion it is legitimate to seek to recover through the planning charge.

A single charge for a local authority area would be unacceptable because land values will vary too much across a local authority area for that to be workable. Different regimes/criteria will need to apply to different parts of a local authority area with different economic/social profiles and different land values. The authority will therefore have the unenviable task of trying to work out how charges should be set for different parts of the area.

In the House of Lords debate in Committee on 2 February 2004, Baroness Hanham asked whether the Government would provide local planning authorities with additional funding for the purposes of establishing the tariff system. In response, Lord Rooker said that under the new proposals, there may be savings as well as costs. He acknowledged that it would be complicated to set up the new system, but once it is bedded in, is likely to lead to less time and resource input in individual applications if people go down the charging tariff route. Once all the guidance is done and once the regulations have been made, if it is a formula he though that it would be a case of fairly mechanical up-front calculations and there ought to be less time spent on it.

Baroness Hanham thought that the system would be far more complicated than someone licking a pen and adding up a formula. Lord Rooker's somewhat naïve glib comments should be treated with some wariness. The crisis in resources in local government should not be underestimated. Many local authorities are working at the limit of their resources. In order to cater for the new system, it is inevitable that additional money, on top of the planning delivery grant, will need to be pumped into council planning departments. One way forward may be to charge developers higher planning fees for planning applications provided that that money is hypothecated to the planning service within that authority.

\section{Impact on development plan documents}

The planning contribution system will be operated through the local planning authorities development plan documents or other presented document. There is a major concern that examinations into drafts of those development plan documents will become bogged down in hearing valuation evidence. The examinations could become more like Lands Tribunal hearings and the Government's aim to have up to date streamlined development plan documents could be undermined. This will again tax the resources of severely stretched local authorities.

With the increased emphasis on community involvement in the planning process, presumably every interest group in a local authority area will be lobbying the local authority for the planning gain that it wishes the council to achieve for their area. This could exacerbate the delays in the development plan process.

\section{Will the optional planning charge be a tax on development?}

Clearly the tariff system promoted by the Government in its December 2001 consultation paper was a form of taxation as it was not related to meeting the cost of mitigating the impact of a development. It was to be a flat rate calculation applied with some flexibility to particular forms of development. What about the optional charge proposals? Are they a tax?

In the House of Commons on 8 December 2003, on the first day of the Report Stage, Keith Hill said that concerns had been raised that the optional charge proposals were a tax on development. He said that that was untrue. He said that the charge would have to relate to planning matters, as the existing system of negotiated obligations does now. Under the Government's proposals, the level of the planning contribution would be set out in advance and in public which would allow it to be tested. The charge will be applied only to the matters identified in the local authority's planning contributions policy. Further, the developer can opt not to pay the charge at all, but to negotiate over what level of contribution to offer.

In the House of Lords debate in Committee on 2 February 2004, Baroness Hanham was concerned to prevent the planning contribution proposals being used as 
a land tax or a development land tax. She said that as it stands, the Bill seems capable of this. She was concerned that such taxes on development might discourage useful development.

Lord Rooker stated that the Government did not see the value capture as a primary function of planning contributions. He said that the main focus should be on addressing the impact of a development with a degree of flexibility to take account of its viability and of economic circumstances. He added that the Government did not want to see planning contributions used explicitly as a means of raising extra revenue unconnected with the development.

A number of commentators have been concerned that there should be some connection between the development proposed and the contribution contained in the local planning authority's planning contribution documents, otherwise the tariff could be construed as being a form of taxation. The Government acknowledged in the ODPM Statement on 30 January 2004 that the planning contribution offered, by whatever route, should be related to the impact of development and be relevant, proportionate and reasonable. This was an important statement and was repeated by Lord Rooker in the House of Lords debate in Committee on 2 February 2004.

The statement undermines the argument put forward by various objectors that the proposals for the optional charge is a form of taxation.

\section{Necessity test}

The Government has changed its mind about the proposal set out in the November 2003 consultation paper to abandon the Circular 1/97 necessity test to bring policy in line with case law and thus to allow planning obligations to be used to contribute to a wider range of impacts for negotiated planning obligations. In its statement on 30 January 2004, the ODPM stated as follows:

"13 The Government has decided that, given the concern which has been expressed about the scope of planning obligations, it should consider further the proposal in its consultation document to align its policy tests with the tests applied by case law to planning obligations. The Government believes that the policy tests set out in Circular 1/97, and in particular the test of "necessity", are not adequately adhered to either by local authorities or by applicants. Case law confirms that applicants may offer benefits not strictly necessary for a development to proceed (which is a policy requirement) but which are nevertheless connected to the development. However, local authorities are constrained in what they can request from developers because of the current policy.

"14 The practice of applicants offering more than local planning authorities think is necessary has caused confusion in local authorities about what they can legitimately ask for.
As the consultation document indicated, the Government does not consider this to be a satisfactory situation, and believes that there may need to be some change to the way in which the policy tests in Circular 1/97 are set out and enforced. The Government will continue to consult with stakeholders on how best to approach this issue".

\section{Agreement even for optional charge}

It had been thought that the Government, in order to justify its claim that the optional charge route would provide speed and certainty, would have encouraged a simple process whereby the developer, if it opted for the charge route, would hand over its financial contribution, calculated in accordance with the local development framework to the local authority and in return would be granted its planning permission. This would be a quick and simple process.

The Government acknowledged however, in the debate in the House of Commons on the first day of the Report Stage on 8 December 2003, that there could be a standard form of agreement set out in the proposed regulations. Keith Hill made it clear that the Government envisaged that the local authority and the developer would need to come to some form of agreement, as they do now, on whether they opt to make the contribution by the prescribed means or the negotiated route. That agreement will bind the developer to pay, and the local authority to accept, the charge agreed at that point. The form of the agreement could be decided between the local authority and the developer or could take a standard form that the Government may prescribe in regulations or issue as guidance. In fact, clause $47(7)$ (b) provides that the regulations may "make provision for setting out in writing the terms of the planning contribution".

If then, there is to be an agreement between the developer and the Council, there is likely by definition to be some form of negotiation. That being so, surely there would then be an opportunity to include provisions relating to the date of payment of the charge and whether this will be phased and covenants by the local planning authority as to how they are to spend the contribution; to allow for the planning authority to give periodic reports as to how the money has been spent and to allow for payback of the sum or any unspent element thereof at an agreed date. These matters could well be the subject of negotiations and would bring certainty to the process. On the other hand, it could slow down the process.

\section{Residual negotiation - slowing down the process}

There will be a possible need for residual negotiation even where the developer elects for an optional charge. Keith Hill acknowledged this in the House of Commons on the first day of the Report Stage on 8 December 2003. He said that where the developer opts to pay the contribution by the prescribed means - the charge, a residual 
negotiation may be necessary to cover matters that could never be covered by the charge. That is likely to be a relatively common occurrence as there will be development control issues that will need to be addressed by a negotiated Agreement. This could have the effect of slowing down the process.

\section{Perversity}

Any housing developer might be encouraged to develop lower density, high value housing if the tariff were to be based on the number of units to be provided rather than on scheme value. A Labour controlled local authority may set zero contributions in a Conservative controlled area, and vice versa. The optional charge system could give local authorities a perverse incentive to favour greenfield developments in order to maximise their income from tariffs.

\section{Enforcement}

It is clear from the new clauses that a person deriving title to land after a commitment to make a planning contribution has been entered into will be bound by the terms of the contribution. Under the existing section 106 arrangements, there is a specific provision whereby an existing owner, once it sells its interest in the land, can escape future liability. There is nothing specific in the new clauses on this. The question arises as to whether the position will be the same under the new arrangements. The clauses seem to be silent on this.

Also on a question of enforcement, the Regulations may provide for a condition to be attached to a planning permission requiring payment of the planning contribution prior to the commencement of the development. That is contained at clause 47(6). In the House of Lords debate at the Committee Stage on 5 February 2004, Baroness Hanham referred to this clause and said she was concerned that planning benefits are often provided over many years as different stages are each in a development. She said that front-loading the contributions would significantly increase financing costs and risks and she suggested an amendment to deal with this.

In response, Lord Rooker said that clearly there would be circumstances in which a planning contribution could not be made prior to the commencement of the development. For example, the development might be economically marginal and the developer might not have funds with which to make a contribution until the development is complete and he gets his return. Lord Rooker pointed out that the local authority would be entitled to vary the condition proposed. In the same way that by default, conditions are attached planning applications limiting their life to five years, local authorities can vary this and local authorities could require planning contributions to be made at times other than at the commencement of the development.
This was an important point of clarification as it will be essential on large scheme that are phased to allow for planning contributions to be phased. It will not matter so much in relation to negotiated contributions as the agreement will set out any agreed phasing of payments.

\section{Controls on how local planning authorities spend money and provisions regarding return of money}

There is a concern that when money is handed over against a tariff to a local authority there is no knowing how that money would be spent. How does one ensure that the money is spent on relevant projects?

There will need to be proper controls on how a planning charge is spent by the local planning authority, otherwise the payment to the authority could be seen as being a naked attempt to buy a planning permission. What if money is not used for the intended purposes? How would local authorities be made to comply?

In the House of Commons on 8 December 2003 on the first day of the Report Stage, Keith Hill said that the Government would anticipate a strenuous local response which would control the situation. Having said that, he said that the Government would have to give serious consideration to the possibility of giving the Secretary of State a reserve power in such circumstances. He said that that was a matter for consideration and consultation after which the Government may come forward with firmer proposals.

As to the tracking of how money is spent by each local authority, Keith Hill said that there should be proper accountability in relation to the spending of income raised by both a charge and the negotiated routes. He said that in the consultation document the Government is proposing that local authorities should set out in public and in advance its policies on contributions for which it would seek a contribution and the matters it spends income on. He said that the Government proposed to take a power to enable the Secretary of State to insist the receipts are spent in the way envisaged in the public planning contributions policy. He also said that the Government proposed a power to require local planning authorities to make an annual report on matters relating to planning contributions. Further, he said that the Government proposed that the Secretary of State should be able to prescribe the procedure by which the charging policy was developed and to take steps if he believed it was not being done appropriately or at all.

In the House of Lords debate at Committee Stage on 5 February 2004, Baroness Hanham said that there was concern to prevent a local authority holding on to money received as a planning contribution indefinitely. She said that there ought to be an amendment whereby the Secretary of State could direct in regulations that after a prescribed period that any money left over would be repaid with interest if not spent on the required purposes. 
Lord Rooker replied by stating that where the parties negotiate, it is likely that the agreement will set out the matters on which the contributions will be spent and provide for repayment if they are not spent by the agreed date. Where the applicant decides to pay the charge, the matters on which the charge will be spent will be contained in the local planning obligations policy. He said that the whole point of the charge is that such matters are laid out in the local planning obligations policy where everyone can see what is required. In short, the provisions ensure that the same redress is available to an applicant who has paid the charge as it is to someone who has negotiated an agreement.

All that the Government is doing is moving the agreement on what the income will be spent on out of the negotiated agreement and into the local planning obligations policy prepared in advance. It is a plan-led approach. The policy will have to be specific enough to give the applicant certainty about what the charge will be spent on otherwise the applicant would simply decide not to pay the charge.

This is not very convincing. An agreement is surely the proper way of controlling the matter with covenants enforceable in the courts.

\section{Will the planning charge remain optional?}

Will not a negotiated agreement always result in a reduced benefit for the local authority - otherwise why would a developer opt for that route? Will a local authority accept that?

Whilst the proposed planning charge is optional, there is scepticism about whether it will remain so. The charge will set the context for planning gain negotiations, particularly so as it would have gone through the development plan process with extensive consultations. The reality may be that the charge set will be too high and will raise expectations of what can be sought from rapacious developers. If one took the negotiated route, it could well be difficult to persuade a local authority to settle for less than that set out in the charge. Negotiations therefore could be somewhat difficult.

\section{Impact on affordable housing}

There have been major concerns expressed that the new system could undermine the provision of affordable housing.

It will be recalled that the Select Committee in their report of 1 July 2002 were concerned that the Government, needed to undertake substantially more work to demonstrate that funding affordable housing by the standardised tariff, rather than by the usual system of Section 106 negotiation would clearly produce significantly more affordable housing.
In the second reading debate on the Bill in the House of Lords on 6 January 2004, Lord Best expressed concern that the current system that obliged builders to allocate land for affordable housing could be bypassed by house builders opting to pay a contribution instead. He said that this would mean that house builders would not have to allocate any part of their developments for affordable housing. Funds raised by such a tariff might not find their way into affordable housing at all, not least because housing associations or other providers of low cost homes might find it impossible to buy the land they need elsewhere.

Further, even if other sites could be purchased, no doubt in the least desirable locations, it would offend good practice to build segregated ghettos of social housing for poorer households rather than integrating these into mixed income, mixed tenure developments with renters alongside owners. He said that tariffs might sensibly replace requirements to include affordable homes in some areas where there was low demand for social, subsidised housing and perhaps also at the very top end of the market where one home for social housing could be replaced by several for the same price elsewhere, but for most of the South of England, and other housing hotspots, tariffs could be a recipe for further reducing the numbers of new, affordable homes unless the tariff system was tailored with great care.

Baroness Hanham was concerned as to the effect that the proposals would have on affordable housing. She said that there were flaws in section 106 but one of its chief advantages is that the money can be used for the local authority's priorities associated with the development. She said that there has probably been more affordable housing built with section 106 money than with any money from the Housing Corporation.

In the debate in the House of Lords on 2 February 2004, Lord Best explained that his own housing association in York, the Joseph Rowntree Housing Trust, had been engaged in a number of developments in recent years. He said that the circumstances of each site were unique. He said that one brown field site was an old refuse tip leaking methane gas where they had to undertake expensive decontamination work. One large green field site had huge pylons and power lines that needed to be buried underground. Special measures will be needed on another site to protect against flooding. He said that we may find the expensive consequences of discovering archaeological remains under one site, while there may be requirements to remove some protected species like the greater crested newt on another site.

A development on one site could bring new viability to a school with falling numbers, but another development will have to be properly charged for the extra education costs flowing from the arrival of more children where there are no available school places.

In one part of any town, gentrification of a neighbourhood that needs renewal would suggest a low 
tariff to attract development and in another part, perhaps close by, a developer will be able to sell for high prices and the local authority will have the chance to go for a higher tariff. The scale of a development will make a major difference, as will its density. There are also variations in the subsidy arrangements for affordable housing which face the developer and any partner housing association. Those financial arrangements will also vary from site to site.

In one case, the Housing Corporation will be able to offer social housing grant worth several hundred thousands of pounds per house so that the housing association can pay the developer something approaching the market price for each affordable home. But in another case, no more funds may be available as grants from the Housing Corporation. If the development is to incorporate affordable housing, the developer will need to put in some serious money. In that case, it is not realistic to expect as many affordable homes as could be supplied if plenty of public money was available.

Lord Best made the point that each case is different and that a negotiation, not a fixed charge or tariff, will be necessary to achieve outcomes that are acceptable to all. At York, the headline aspirational target of the council is for 50 per cent of affordable housing to meet its pressing needs. But it has to accept lower figures of half, or less than half, where the constraints on the developer make it impossible to achieve such a high quota. He said that no fixed tariff could cover all those circumstances, and if an authority were to go down that route, he said that there could be long delays in trying to calculate the level of tariffs, as has been suggested. Once those levels are announced, they are likely to lead to disagreements, appeals, calls for judicial reviews or further delays as one size may not fit more than one site.

It was also said by Lord Best that the Minister suggested developers could simply reject the offer of the alternative system of tariffs and choose to stay with the current section 106 negotiations thereby having nothing to do with the new system. But the developer will worry that once the local authority has set up its system of tariffs it will be under some pressure to accept them. It will fear that once the tariff system is set up, developers who reject will find that all the current problems facing section 106 agreements are not likely to be cured. Current delays include there being no skilled planners able to negotiate at a sophisticated level, a lack of co-ordination between relevant public bodies and the lack of a mediator or arbitrator to help the process. The problems facing section 106 agreements may still be there and may be worse if the local authority chooses a system of tariffs instead and developers will feel under some pressure to accept them.

Lord Best suggested therefore that it was not likely that we will be able to find the ways in which tariffs could be applied to anything more than a single site at a time. If you have a tariff which you apply to only one site at a time, you do not have a tariff, you have a negotiation site by site. If we are to have a negotiation, let us improve the section 106 agreements that do just that - negotiate site by site. There is good mileage in that.

The concern was raised by Lord Best that in some local authorities, the chance to take alternative more electorally popular benefits from the developer could be seized upon. He said that people living beside a planned development will always have a shopping list of alternatives to affordable housing which tariff homes could cover - local amenities and facilities, improvements to the roads around the site, environmental enhancement and so on. That could have a severe impact on the amount of affordable housing being provided.

Lord Best concluded that clause 46 should not be in the Bill, partly because of the practical difficulties posed, but partly because of the dangers it was feared it posed to the provision of affordable housing. Under the current section 106 agreement, elaborate provisions are regularly negotiated between developers and local planning authorities to secure affordable housing provision usually on site and increasingly in more than one location on site to aid the concept of balanced communities and avoiding creation of ghettos. Local planning authorities, through section 106 agreements, control the construction and deliver of the affordable housing and ensure that the affordable housing units will be available in perpetuity as affordable housing, usually through the medium of a registered social landlord. Nomination rights are often negotiated and service charges capped with the provisions being contained within the section 106 agreement.

If a developer opts for the charge route in relation to a particular scheme, and even if the developer offers affordable housing in kind in accordance with the local authority's policies, how will the local planning authority be able to secure, as they do now, the actual delivery of the housing on site and future controls over that affordable housing? Conceivably, the authority could impose a planning condition relating to the delivery of that affordable housing, but a condition could not achieve the same sophisticated controls with an element of mutuality as exists under the present section 106 system. Lord Best's concerns regarding the impact of the optional charge on the provision of affordable housing are real ones.

\section{HOW WILL PLANNING CONTRIBUTIONS WORK?}

The essential question posed in this paper is "How will planning contributions work?".

To the extent that developers opt for planning contributions to be dealt with as they are now, by way of negotiated agreements, then there is every reason to think that they will work well - business as usual. The only potential cloud on the horizon may be how wide the necessity test is drawn in policy terms in the replacement 
Circular for Circular 1/97. It may be drawn wider than the existing necessity tests as the Government seeks to ensure that developers contribute to sustainable development which might be more than purely dealing with the impact of a development.

Will local planning authorities be reasonable if a developer opts for the negotiated route? The developer will no doubt have seen an advantage in pursuing the negotiated route, the obvious point being that he sees that as being less expensive than paying the tariff. The local authority may sense that and may try and make life difficult for the developer in the negotiation. That could mean that the developer has to take the matter to appeal with the expense and delay that that would entail. That surely cannot be satisfactory.

To the extent that developers pursue the optional charge route, it is anybody's guess how the system will work. With only skeleton provisions being available in the Bill and without benefit of a sight of the proposed draft regulations or the Government's proposed draft Circular, it is hard to know how the optional charges will operate. The Government has at least now agreed to set up pilot schemes to test out the optional charge and thankfully has taken on board advisers in the form of the task force to think through the tariff proposals and how they might work in practice. Judgment will therefore have to be reserved on the workability of the optional charge until an assessment can be made as to how any pilot scheme has worked and to see whether there are any practical problems and until the views of the task force have been received and analysed.

The Government should also not lose sight of the local authority resource issue which could have an impact on the workability of optional charges and the slowing effect they could have on adoption of development plan documents.

If the Government were to accept Kate Barker's proposed planning gain supplement, then that would undoubtedly spell the demise of the optional planning charge, as the systems would be in conflict with each other. It may be therefore that the optional charge will be a shortlived measure, even assuming it ever gets off the ground.

\section{Michael Cunliffe}

Partner, Forsters Solicitors

Michael specialises in planning law. He is a Legal Associate of the Royal Town Planning Institute and member of the Law Society's Specialist Planning Panel. He is a member of the Planning and Environmental Law Reform Working Group of the Society for Advanced Legal Studies and a member of the City of London Law Society's Planning and Environmental Law Sub-Committee. Michael has developed a particular expertise in the field of planning obligations/planning gain and he has negotiated numerous complex agreements both on behalf of developers and local planning authorities. Michael has lectured on planning law and written articles for planning journals. He gave a paper at the Oxford Joint Planning Law Conference in September 2001 entitled "Planning obligations - where are we now?"

(C) Forsters LLP 2004 